\title{
STRATEGI PENGEMBANGAN PELABUHAN SUNDA KELAPA SEBAGAI GERBANG WISATA SEJARAH DI JAKARTA
}

\author{
Novi Handayani \\ Program Studi Magister Manajemen Universitas Tarumanagara \\ widuri1992@gmail.com
}

\begin{abstract}
This research was conducted with the aim to see the potential of Sunda Kelapa Port through the resources possessed by the theory of Resource Based View (RBV) and then look for strategies that can be used to develop historical tourism in the Sunda Kelapa Port. The informant and respondent of this research is PIC acceleration of the old city area of the Ministry of Tourism, PT Pelindo II, Tour Guide, and tourists. Data collected by observation, interview, literature study and questioner. This research used qualitative descriptive method in order to analyze the data that have been collected by using IFE and EFE matrix, IE Matrix, SWOT Matrix and QSPM matrix. Based on the analysis and discussion that has been described, the product development strategy is the main strategy that must be developed by Sunda Kelapa Port to be able to compete with other tourist destinations.
\end{abstract}

Abstrak: Penelitian ini dilakukan dengan tujuan untuk melihat potensi yang dimiliki oleh Pelabuhan Sunda Kelapa melalui sumber daya yang dimiliki dengan teori Resource Based View (RBV) kemudian mencari strategi yang dapat digunakan untuk mengembangkan wisata sejarah Pelabuhan Sunda Kelapa. Informan dan responden penelitian ini adalah PIC percepatan kawasan kota tua dari Kementerian Pariwisata, PT Pelindo II, Pemandu Wisata, dan wisatawan. Data dikumpulkan dengan observasi, wawancara, studi pustaka dan kuesioner. Penelitian ini menggunakan metode deskriptif kualitatif untuk menganalisis data yang telah dikumpulkan dengan menggunakan matriks IFE dan EFE, Matriks IE, matriks SWOT dan matriks QSPM. Berdasarkan analisis dan pembahasan yang telah diuraikan, maka strategi product development merupakan strategi utama yang harus dikembangkan oleh Pelabuhan Sunda Kelapa untuk dapat bersaing dengan destinasi wisata lainnya.

Keywords : Strategic management, Tourism, Pelabuhan Sunda Kelapa, SWOT analysis

\section{PENDAHULUAN}

Pariwisata merupakan salah satu sektor ekonomi unggulan yang paling cepat pertumbuhannya di dunia. Oleh karena itu, banyak negara yang sudah dengan serius mengembangkan sektor pariwisatanya. Indonesia sendiri ada di urutan ke 42 dalam ranking pariwisata, tertinggal dengan Malaysia, Thailand dan Singapura yang masing-masing berada di ranking 26,34 dan 13 (The Travel \& Tourism Competitiveness report 2017). Indonesia harusnya bisa berada di peringkat yang lebih tinggi mengingat Indonesia merupakan negara dengan 13.466 pulau yang terbentang dari sabang sampai merauke, ratusan etnis budaya, serta tempat-tempat eksotis yang menarik untuk dijelajahi.

Berdasarkan data dari Kementrian Pariwisata, kontribusi sektor pariwisata terhadap BDP Indonesia pada tahun 2014 adalah sebesar $9 \%$ sedangkan target kontribusi untuk tahun 2019 adalah pada kisaran $15 \%$. Tentunya untuk mencapai target tersebut masih banyak hal yang perlu dibenahi. Pariwisata sendiri ada berbagai macam jenisnya, menurut James J. Spillane (1987:29-31) pariwisata terbagi ke dalam 6 jenis yaitu: 1) Pleasure Tourism 2) Recreation Tourism 3) Cultural Tourism 4) Sports Tourism 5) Business Tourism 6) Convention Tourism. 
Dalam penelitian ini, jenis pariwisata yang diteliti adalah Cultural Tourism khususnya historical and heritage tourism.

Ada banyak tempat bersejarah yang ada di Jakarta dan sangat menarik untuk dikunjungi salah satunya adalah pelabuhan Sunda Kelapa. Pelabuhan Sunda Kelapa merupakan pelabuhan tertua di Indonesia yang telah ada sejak abad ke 5. Dahulu, pelabuhan Sunda Kelapa merupakan pelabuhan paling penting bagi aktifitas perdagangan di Indonesia di masa kerajaan sunda. Pada masa itu, Pelabuhan Sunda Kelapa merupakan pusat perdagangan rempah-rempah terbesar di Benua Asia.

Saat ini jumlah kunjungan ke pelabuhan Sunda Kelapa masih kurang dari segi pengunjung padahal pelabuhan sunda kelapa memiliki banyak potensi untuk menarik lebih banyak wisatawan seperti tempat-tempat wisata lainnya. Dari observasi yang telah peneliti lakukan, beragam keunikan dan potensi yang dimiliki oleh Pelabuhan Sunda Kelapa sebagai sebuah tempat wisata masih belum tergambar dengan baik. Hal ini bisa jadi terkait dengan fungsi Pelabuhan Sunda Kelapa yang juga merupakan pelabuhan aktif di bawah naungan PT Pelindo II sehingga fungsi Pelabuhan Sunda Kelapa sebagai kawasan wisata masih belum diprioritaskan. Apabila hal ini terus berlanjut bisa jadi Pelabuhan Sunda Kelapa lamakelamaan kehilangan fungsinya sebagai tempat wisata bersejarah yang ada di Jakarta. Oleh karena itu peneliti tertarik untuk melakukan penelitian yang berjudul "Strategi Pengembangan Pelabuhan Sunda Kelapa Sebagai Gerbang Wisata Sejarah Di Jakarta"

\section{Identifikasi Masalah}

Berdasarkan paparan latar belakang di atas, peneliti tertarik untuk menggali daya tarik serta yang potensi dimiliki oleh Pelabuhan Sunda Kelapa. Kemudian, peneliti ingin mengetahui lebih jauh bagaimana strategi pengembangan Pelabuhan Sunda Kelapa sebagai Wisata Sejarah di Jakarta.

\section{Tujuan Penelitian}

- Untuk mengetahui gambaran destinasi wisata Pelabuhan Sunda Kelapa berdasarkan teori Resource Based View (RBV)

- Untuk merumuskan strategi pengembangan Pelabuhan Sunda Kelapa yang tepat untuk dapat menjadi gerbang wisata sejarah di Jakarta.

\section{TELAAH PUSTAKA}

\section{Definisi Wisata Sejarah}

Menurut (Saputro, Adi, 2017) potensi pariwisata berbasis sejarah budaya merupakan salah satu aset yang berpotensi untuk dikembangkan oleh setiap daerah. Wisata budaya sejarah, ketika dikombinasikan dengan liburan dan atraksi wisata dapat diperhitungkan sebagai fenomena wisata paling signifikan dan cepat perkembangannya di dunia (Martin \& Mason, 1992; waters, 1994, herbert, 1995 dalam ALzua, O’Leary \& Morrison, 1998). Sebuah negara harus mengembangkan wisata sejarah budaya mereka untuk menarik lebih banyak turis internasional. Salah satu cara untuk membuat sebuah wisata sejarah budaya dapat membuat pengunjungnya dapat terlayani dengan baik dan dapat memahami wisata sejarah budaya itu sendiri adalah melalui program pemasaran, perencanaan/strategi dan pemrograman dengan penduduk lokal dan regional.

Indonesia sendiri memiliki situs wisata sejarah di hampir setiap kota yang ada, namun sayangnya belum semua destinasi wisata sejarah yang ada dapat dimanfaatkan semaksimal mungkin, kondisi bangunan sejarah yang tidak terawat hingga sarana dan prasarana yang kurang memadai merupakan kendala klasik yang hingga saat ini masih terjadi. Sesuai dengan penelitian yang dilakukan oleh Adi, Waskito dan Saputro, Purwo (2017) bahwa persoalan tentang degradasi nilai dan fungsi bangunan menjadi tantangan bagi setiap situs wisata sejarah yang mempengaruhi minat kunjungan wisatawan yang dengan kata lain memberi dampak negatif terhadap pengembangan kepariwisataan berbasis sejarah budaya. 


\section{Pelabuhan Sunda Kelapa}

Pelabuhan Sunda Kelapa merupakan Pelabuhan tertua di Indonesia dan merupakan cikal bakal dari Ibu Kota Jakarta. Saat ini Sunda Kelapa dijadikan kawasan wisata di bawah pengembangan kawasan Kota Tua karena nilai sejarahnya yang tinggi. Kini selain menjadi tempat aktifitas bongkar muat, Sunda Kelapa juga menjadi salah satu objek wisata unggulan di Jakarta di bawah zona wisata Kota Tua. Dikarenakan daya tarik sejarahnya yang kuat bila berkunjung ke Sunda Kelapa mungkin akan bertemu dengan beberapa wisatawan lain baik dari dalam negeri mau pun mancanegara namun jumlahnya tidak sebanyak dengan jumlah wisatawan di sekitaran museum fatahillah padahal Sunda Kelapa juga memiliki potensi wisata yang sangat menarik. Pelabuhan Sunda Kelapa kini berada di bawah pengelolaan PT Pelindo sementara untuk kegiatan wisatanya dinaungi oleh DMO ( Destination Management Operation) Zona Kota Tua.

\section{Strategi}

Berdasarkan buku Strategic Management for Travel \& Tourism karangan Nigel Evans, David Campbell dan George Stonehouse (2003) strategi merupakan sebuah proses, strategi akan selalu berkembang sesuai dengan lingkungan yang selalu berubah. Sedangkan menurut David, Fred R (2009) strategi diartikan tindakan-tindakan potensial yang dibuat untuk mencapai tujuan jangka panjang. Secara lebih rinci menurut Chandler definisi strategi adalah penentuan tujuan jangka panjang serta penerapan tindakan yang diperlukan untuk melaksanakan tujuan tersebut. Sedangkan menurut Minzberg strategi dapat diartikan sebagai 5P yaitu Plan (rencna), Ploy ( Cara), Pattern of behavior ( pola prilaku), Position in respect to others (posisi untuk menghargai seseorang) dan Perspective (sudut pandang). Dalam penelitian ini, strategi yang dimaksud adalah rencana-rencana yang dibuat dalam rangka mengembangkan potensi wisata di kawasan Sunda Kelapa

\section{Resource Based View}

Menurut Pearce, Robinson (2014) RBV merupakan suatu alat untuk menganalisis dan mengidentifikasikan keunggulan strategis yang didasarkan pada tinjauan terhadap kombinasi dari sumber daya yang dimiliki. Untuk menggunakan RBV sebagai tools analisis internal, harus diidentifikasi dan dievaluasi terlebih dahulu sumber-sumber daya yang ada untuk pada akhirnya menemukan sumber daya mana yang dapat menjadi dasar bagi keunggulan kompetitif masa depan.

\section{METODOLOGI PENELITIAN \\ Metode Kualitatif Deskriptive}

Untuk menjawab dan memecahkan permasalahan yang dirumuskan di atas, diperlukan kerangka konsep atau model yang merupakan abstraksi dari penelitian ini. Oleh karena itu metode kualitatif descriptive dirasa paling cocok untuk penelitian jenis pengembangan ini. Menurut Cresswel (2014) metode kualitatif bergantung pada data teks dan gambar, memiliki langkah-langkah unik dalam analisis datanya dan menarik beragam desain. Penelitian kualitatif bertujuan untuk menjawab pertanyaan "apa" "bagaimana" dan "mengapa".

\section{Subjek dan Informan Penelitian}

Subjek penelitian dalam penelitian ini adalah Pelabuhan Sunda Kelapa. Informan dalam penelitian ini yaitu PIC percepatan kawasan kota tua dari Kementrian Pariwisata, pihak pelabuhan (PT Pelindo II), Tour Guide, dan wisatawan.

\section{Prosedur Pengumpulan Data}

- Observasi merupakan pengambilan catatan lapangan dan aktifitas individu di tempat penelitian yang dilakukan oleh peneliti (Cresswel, 2014). Observasi yang dilakukan pada penelitian ini dimulai dari Bulan Januari 2017 hingga kurun waktu Juli 2018. 
- Wawancara merupakan pengumpulan yang "wajib" ada dalam penelitian kualitatif. Dalam penelitian ini, ada empat pihak yang diwawancara sebagai perwakilan yang terlibat langsung dalam perkembangan Pelabuhan Sunda Kelapa,

- Dokumen merupakan salah satu tipe pengumpulan data kualitatif. Dokumen yang dikumpulkan dalam penelitian ini yaitu list jumlah data pengunjung dari tahun 2011-2017 \& SK pergub no. 36 tahun 2014

- Dalam penelitian kualitatif, kuesioner bersifat untuk membantu dalam proses analisis data. Pada penelitian ini, kuesioner disebar setelah dilakukan wawancara dan observasi, tepatnya setelah peneliti mendapat hasil dari analisis internal dan eksternal. Kuesioner diberikan kepada 20 orang responden yang pernah mengunjungi Pelabuhan Sunda Kelapa, disertakan juga dua orang dari Kementrian Pariwisata, beberapa Tour Guide, serta masyarakat yang pernah berkunjung ke Pelabuhan Sunda Kelapa

\section{Teknik Analisis Data}

Menurut Bandur (2014) analisa data dalam penelitian kualitatif cenderung dari analisis teks dan gambar, tema-tema serta pola-pola yang luas dan generalisasi. Teknik analisis data dalam penelitian ini yang pertama menggunakan analisis matriks evaluasi faktor internal (IFE) dan matriks evaluasi faktor eksternal (EFE), kemudian tahap kedua menggunakan matriks IE, matriks SWOT dan matriks QSPM.

\section{ANALISIS DAN BAHAN TEMUAN}

\section{Analisis Internal (Resource Based View)}

Analisis Internal yang digunakan dalam penelitian ini adalah RBV (Resource Based View). Analisis ini cukup umum digunakan pada penelitian yang berbasis pariwisata. Sesuai dengan penjabaran pada Bab II tentang RBV yang digunakan pada penelitian ini, berikut merupakan cakupan sumber daya yang dimiliki oleh Pelabuhan Sunda Kelapa :

- Physical Resource yang didalamnya mencakup sumber daya alam, transportasi dan akomodasi dan infrastuktur

- Human Resource

- Financial Resource

- Aset Budaya termasuk di dalamnya sejarah dan makanan khas

- Atraksi Spesial

- Keamanan dan Keselamatan

\section{Analisis Eksternal}

Analisis Eksternal yang digunakan dalam penelitian ini menggunakan analisis lingkungan jauh (External Key Forces) terbagi ke dalam 5 kategori besar yaitu:

- Ekonomi

Faktor ekonomi sangat memengaruhi orang dalam memakai dana yang dimilikinya, terlebih untuk kegiatan wisata yang merupakan kebutuhan tersier.

- Sosial, budaya, demografis,dan lingkungan

Kondisi sosial dan budaya yang ada di sekitar lingkungan objek wisata akan mempengaruhi keputusan wisatawan untuk berkunjung. Kebanyakan wisatawan tidak hanya datang untuk mengunjungi objek tetapi juga untuk melihat kehidupan sosial dari wilayah objek wisata, bagaiman penduduk lokalnya dan bagaimana kondisi lingkungannya.

- Politik, pemerintahan dan hukum

Kondisi politik, pemerintahan dan hokum sudah jelas berdampak pada industry pawisata. Dapat dilihat untuk beberapa Negara yang kondisi pemerintahannya tidak stabil serta banyak gejolak internal terjadi akan membuat wisatawan enggan untuk berkunjung ke daerah tersebut. 
- Teknologi

Teknologi tentunya juga memengaruhi industri pariwisata, terlebih dengan adanya Internet yang membuat informasi dari berbagai belahan dunia bisa diakses dengan hanya melalui Gadget.

- Persaingan/Kompetisi

Pesaing objek wisata Sunda Kelapa sudah pasti tempat wisata lainnya. Kelemahan objek wisata Sunda Kelapa dengan pesaingnya adalah permasalahan kenyamanan, hal ini terkait dengan kondisi pelabuhan yang tidak begitu ramah untuk pengunjung. Namun, tidak dapat dipungkiri bahwa sejarah yang dimiliki oleh Pelabuhan Sunda Kelapa tidak dapat digantikan oleh tempat wisata lainnya dan merupakan kekuatan yang menjadi daya tarik objek wisata ini.

\section{Matriks IFE dan EFE}

Dari penjabaran analisis internal dan external di atas, berikut merupakan hasil dari matriks IFE dan EFE Pelabuhan Sunda Kelapa sebagai objek wisata sejarah :

\begin{tabular}{|c|c|c|c|}
\hline Faktor Internal & Bobot & Rating & $\begin{array}{c}\text { Skor } \\
\text { Terbobot }\end{array}$ \\
\hline \multicolumn{4}{|c|}{ KEKUATAN } \\
\hline $\begin{array}{l}\text { Merupakan pelabuhan tertua di } \\
\text { Indonesia }\end{array}$ & 0.06 & 3.25 & 0.19854 \\
\hline $\begin{array}{l}\text { Merupakan cikal bakal ibukota } \\
\text { Jakarta }\end{array}$ & 0.06 & 3.15 & 0.18651 \\
\hline $\begin{array}{l}\text { Memiliki latar belakang sejarah } \\
\text { yang menarik }\end{array}$ & 0.06 & 3.4 & 0.21729 \\
\hline $\begin{array}{l}\text { Atraksi kapal phinisi yang menarik } \\
\text { (bentuk,philosophi, harga) }\end{array}$ & 0.06 & 3.1 & 0.18064 \\
\hline Atraksikeliling perahu & 0.06 & 3.15 & 0.18651 \\
\hline Aktifitas bongkar muat & 0,05 & 2.6 & 0.12707 \\
\hline $\begin{array}{l}\text { Memiliki Spot } \text { Foto yang } \\
\text { Instagrammable }\end{array}$ & 0.06 & 3.35 & 0.21095 \\
\hline Harga tiket yang murah & 0.06 & 3.45 & 0.22373 \\
\hline $\begin{array}{l}\text { Marima Batavia yang merupakan } \\
\text { restoran menarik dan dapat } \\
\text { menyewa kapal }\end{array}$ & 0.05 & 2.8 & 0.014737 \\
\hline \multicolumn{4}{|c|}{ KELEMAHAN } \\
\hline $\begin{array}{l}\text { Kurangnya kemasan wisata yang } \\
\text { ciamik }\end{array}$ & 0.05 & 2.4 & 0.10827 \\
\hline $\begin{array}{l}\text { Belum ada jalur yang terpisah } \\
\text { antara turis dan truk yang lalu } \\
\text { lalang }\end{array}$ & 0.07 & 3.8 & 0.27143 \\
\hline $\begin{array}{l}\text { Tourism Information Centre yang } \\
\text { tidak terurus dan terawatt }\end{array}$ & 0.07 & 3.6 & 0.24361 \\
\hline $\begin{array}{l}\text { Belum ada prosedur keamanan dan } \\
\text { keselam atan dari wisata keliling } \\
\text { perahu ( } / \text { safety jacket) }\end{array}$ & 0.05 & 2.7 & 0.13703 \\
\hline $\begin{array}{l}\text { Belum ada tempat makan yang } \\
\text { bervariasi }\end{array}$ & 0.06 & 3.4 & 0.21729 \\
\hline Akses yang macet & 0.04 & 2.1 & 0.08289 \\
\hline $\begin{array}{l}\text { Belum ada penghubung antara } \\
\text { jalanan dan dek kapal }\end{array}$ & 0.06 & 3.35 & 0.21095 \\
\hline Kondisi panas dan berdebu & 0.07 & 3.6 & 0.24361 \\
\hline Jumlah & 1 & & 3.1937 \\
\hline
\end{tabular}

\begin{tabular}{|c|c|c|c|}
\hline Faktor External & Bobot & Rating & $\begin{array}{c}\text { Skor } \\
\text { Terbobot }\end{array}$ \\
\hline \multicolumn{4}{|c|}{ PELUANG } \\
\hline $\begin{array}{l}\text { Merupakan bagian dari wisata } \\
\text { Kota Tua yang dicanangkan } \\
\text { sebagai 10 Bali baru di } \\
\text { Indonesia }\end{array}$ & 0.12 & 3 & 0.34682 \\
\hline $\begin{array}{l}\text { Program pengembangan daerah } \\
\text { wisata kota tua yang telah } \\
\text { berjalan dengan baik }\end{array}$ & 0.10 & 2.7 & 0.28092 \\
\hline $\begin{array}{l}\text { Meningkatnya minat kunjugan } \\
\text { wisatawan asing ke Indonesia }\end{array}$ & 0.13 & 3.3 & 0.41965 \\
\hline $\begin{array}{l}\text { Merupakan satu dari } 12 \text { jalur } \\
\text { tujuan wisata pesisir Jakarta } \\
\text { Utara }\end{array}$ & 0.12 & 3.2 & 0.39461 \\
\hline $\begin{array}{l}\text { Sedang digalakkannya proses } \\
\text { revitalisasi kawasan heritage }\end{array}$ & 0.13 & 3.3 & 0.41965 \\
\hline \multicolumn{4}{|c|}{ ANCAMAN } \\
\hline $\begin{array}{lrr}\text { Kurangnya } & \text { pemahaman } \\
\text { masyarakat akan } & \text { pentingnya } \\
\text { sejarah } & & \end{array}$ & 0.08 & 2.2 & 0.18651 \\
\hline $\begin{array}{lcc}\text { Force } & \text { Majored } & \text { seperti } \\
\text { banjir/kenaikan air laut } & \\
\end{array}$ & 0.12 & 3.2 & 0.39461 \\
\hline $\begin{array}{l}\text { Terorisme yang } \begin{array}{r}\text { dapat } \\
\text { mmengurangi } \\
\text { wisatawan asing }\end{array} \\
\text { kunjungan }\end{array}$ & 0.09 & 2.35 & 0.21281 \\
\hline $\begin{array}{l}\text { Jumlah kapal phinisi yang } \\
\text { semakin berkurang }\end{array}$ & 0.10 & 2.7 & 0.28092 \\
\hline Jumlah & 1.00 & & 2.93651 \\
\hline
\end{tabular}




\section{Matriks IE}

Dari hasil analisis IFE dan EFE yang telah dilakukan sebelumnya, berikut merupakan hasil posisi matriks IE dari Pelabuhan Sunda Kelapa:

\begin{tabular}{|c|c|c|c|}
\hline EFE & & IFE & \\
\hline & Strong $(3.0-4.0)$ & Average $(2.0$ - 2.9) & Weak $(1.0-1.9)$ \\
\hline $\begin{array}{l}\text { High } \\
(3.0-4.0)\end{array}$ & I & II & III \\
\hline $\begin{array}{l}\text { Medium } \\
(2.0-2.9)\end{array}$ & & V & VI \\
\hline $\begin{array}{l}\text { Weak } \\
(1.0-1.9)\end{array}$ & VII & VIII & IX \\
\hline
\end{tabular}

Nilai EFE untuk Pelabuhan Sunda Kelapa adalah 2.93651 dan nilai IFE nya adalah 3,1937 sehingga Pelabuhan Sunda Kelapa menempati kolom IV yang artinya posisi IFE dan EFE berada di posisi yang cukup kuat sehingga strategi yang tepat untuk Pelabuhan Sunda Kelapa adalah Grow and Build.

Setelah mendapatkan posisi Pelabuhan Sunda Kelapa pada IFE dan EFE matriks, peneliti membuat strategi-strategi yang dapat digunakan yang diolah dalam matriks SWOT kemudian utama

\section{KESIMPULAN DAN SARAN}

\section{Kesimpulan}

Berdasarkan uraian, analisis dan pembahasan hasil penelitian mengenai strategi pengembangan Pelabuhan Sunda Kelapa sebagai gerbang wisata sejarah di Jakarta, dapat disimpulkan sebagai berikut:

\section{Strategi untuk product development yaitu :}

- Memperbaiki kemasan wisata sehingga lebih menarik

- Mengajukan perbaikan fasilitas turis

- Bekerja sama dengan pemprov untuk membuat jalur khusus turis

- Bekerja sama dengan pemprov untuk menyediakan spot foto yang aman

- Membuat diorama Sunda Kelapa untuk para pengunjung.

- Memastikan kelangsungan keberadaan kapal phinisi.

- Membuat VR (Virtual Reality) untuk memperlihatkan kondisi Pelabuhan Sunda Kelapa di Masa lalu

\section{Strategi untuk Market Penetation yaitu :}

- Menambah kegiatan promosi kawasan wisata

- Mengadakan sosialisasi ke masyarakat \& sekolah-sekolah untuk mengunjungi kawasan heritage sunda kelapa.

Strategi untuk Market Development yaitu :

- Bekerja sama dengan travel agent dan hotel untuk dijadikan opsi kunjungan wisata

Strategi untuk Forward Integration yaitu :

- Membuat paguyuban perahu

- Memberikan training kepada awak kapal dan pemilik kapal tentang aturan safety

- Menyediakan bagian yang dapat mengantisipasi bencana dan tindakan kriminal. (Forward Integration)

\section{Strategi untuk Horizontal Integration yaitu :}

- Melakukan kerjasama dengan wisata di sekitar untuk membuat kegiatan bersama 
Sedangkan dari hasil tabel QSPM berikut merupakan 6 strategi prioritas dari 14 strategi yang telah dibuat :

- Mengajukan perbaikan fasilitas untuk turis (S4)

- Memperbaiki kemasan wisata sehingga lebih menarik (S3)

- Bekerja sama dengan travel agent dan hotel untuk dijadikan opsi kunjungan wisata (S1)

- Mengadakan sosialisasi ke masyarakat dan sekolah-sekolah untuk mengunjungi kawasan heritage Pelabuhan Sunda Kelapa (S5)

- Melakukan kerjasama dengan wisata sekitar untuk membuat kegiatan bersama (S2)

- Memberikan training kepada seluruh penyedia atraksi mengenai aturan safety (S6)

\section{Saran}

Berdasarkan kesimpulan yang telah dipaparkan di atas, maka peneliti memberikan saran sebagai berikut :

- Pengembangan kawasan wisata Pelabuhan Sunda Kelapa dapat memberikan keuntungan bagi seluruh elemen pembentuknya sehingga perbaikan-perbaikan yang dilakukan tidak akan membuat kerugian bagi pemerintah mau pun pihak Pelabuhan itu sendiri. Dengan ramainya area Pelabuhan Sunda Kelapa, industri pariwisata mendapatkan keuntungan secara finansial sehingga perekonomian masyarakat meningkat.

- Untuk Pemereintah daerah harus lebih memperhatikan kondisi wisata di Pelabuhan Sunda Kelapa dengan memperbaiki produk wisata yang dimiliki sebagai saran utama agar pengunjung dapat lebih nyaman saat berkunjung.

- Instansi terkait harus lebih gencara lagi melakukan promosi Kawasan Wisata Sunda Kelapa agar lebih banyak orang yang mengetahui dan berkunjung.

Daftar Pustaka

WEF. (2017). The Travel \&amp; Competitiviness Report 2017: Paving the way for a more sustainable and inclusive future. https://doi.org/ISBN-13: 978-1-944835-08-8

Adi, S. W., Surakarta, U. M., \& Surakarta, U. M. (2017). Potensi daya tarik wisata sejarah budaya, (February), 475-481.

Kemenpar. (2016). Pembangunan destinasi pariwisata prioritas 2016 - 2019. Rapat Koordinasi Nasional Kementerian Pariwisata "Akselerasi Pembangunan Kepariwisataan Dalam Rangka Pencapaian Target 12 Juta Wisman Dan 260 Juta Wisnus 2016," 76.

Lohnman,G. (2004). Tourism and Transport Relationship: The Supplier's perspective in gateway destination in New Zealand. Asia Pacific Journal of Tourism Research 17(1):14-29

Spillane, James J. (1987). Ekonomi Pariwisata, Sejarah dan Prospeknya. Kanisius

O'Leary, Joseph T.; Morrison, Alastair M.; Alzua, Aurkene. (1998). Cultural and heritage tourism: identifying niches for international travelers. Journal of Tourism Studies, Vol. 9, No. 2, Dec 1998: 2-13

Creswell, J.W., (2014). Research Design : Qualitative, Quantitative and Mixed. Methods Approaches : fourth edition. Sage publications, Inc. Halim, A., 2014.

Agustinus Bandur, P. (2014). PENELITIAN KUALITATIF, Metodologi, Desain \&. Teknik Analisis Data dengan NVIVO 10. Jakarta: Mitra Wacana Media. o

David, Fred R. 2010. Strategic Management: A Competitive Advantage Approach, Concepts and Cases (13th Edition). UAS :Prentice Hall.

Freddy Rangkuti. 2005. Analisis SWOT : Teknik Membedah Kasus. Bisnis. Jakarta: PT. Gramedia. 
